\title{
Acute hyperammonemic encephalopathy - an indication for an extracorporeal depuration technique A case report and literature review
}

\author{
Filipa Silva*,1, Joana Tavares ${ }^{*}{ }^{1}$, Ana Castro ${ }^{1}$, Arlindo Guimas ${ }^{2}$, Cristina Freitas $^{1}$, João Pedro Pimentel ${ }^{1}$, António Cabrita $^{1}$ \\ * Shared co-first authorship: Both authors have contributed equally to this publication. \\ ${ }^{1}$ Serviço de Nefrologia do Centro Hospitalar Universitário do Porto. Largo do Prof. Abel Salazar 4099-001 Porto, Portugal. \\ 2 Unidade Intermédia Médico-Cirúrgica do Centro Hospitalar Universitário do Porto. Largo do Prof. Abel Salazar 4099-001 Porto, Portugal.
}

\section{ABSTRACT}

Introduction: Ammonia is a resultant molecule from the protein metabolism that can be neurotoxic when present in high concentrations, causing brain edema and encephalopathy. Extracorporeal blood purification technique (EBPT) can play a role in reducing both ammonia and urea blood levels. However, there are no specific guidelines for its use in hyperammonemia, due to its low incidence and scarce literature on this subject, particularly in adults. Case report: The authors describe a case of a 22-year-old previously healthy woman. She presented with polyuria, polydipsia, anorexia, vomiting and significant (>10\%) weight loss over a month. Laboratory data revealed hypoglycemia and a high anion gap metabolic acidosis with severe acidemia with normal lactate, serum creatinine of $1.12 \mathrm{mg} / \mathrm{dl}$ and 260 (reference value 26-74) umol/l of ammonia. Urine analysis showed ketone bodies. She evolved with progressive encephalopathy and neurological deterioration. The hypothesis of hyperammonemic encephalopathy secondary to a hereditary metabolic disease was suspected. Medical supportive therapy was initiated. An EBPT for ammonia removal and acid-base correction was initiated using continuous venovenous hemodiafiltration (CVVHDF) with a drastic neurologic improvement. A fatty acid beta-oxidation deficit was discovered. The patient was discharged with no neurological changes, with a strict diet free of fat, animal protein and high-protein vegetables, plus supplementation with benzoate, carnitine, riboflavin, maltodextrine and essential amino acids. Discussion and conclusion: In adults, hyperammonemia related to metabolic disorders is rare, and in the presence of encephalopathy, ECDT should be considered. Ammonia is easily dialysable either by intermittent or continuous techniques. CVVHDF provides a continuous clearance with less rebound effect.

Key-words: hyperammonemia, encephalopathy, extracorporeal dialysis

\section{INTRODUCTION}

Ammonia is a resultant molecule from the normal protein metabolism, but in high concentrations can be toxic and lead to severe neurological dysfunction, with irreversible cerebral damage ${ }^{1}$. Ammonia intoxication can occur in patients with urea cycle defects, organic acidemias, fatty acid oxidation defects, liver failure, Reye syndrome, post-chemotherapy or due to exposure to various toxins or drugs ${ }^{1}$.

The metabolism of ammonia depends on the enzymatic activity of multiple organs, including kidneys, liver, muscle, intestine and brain. The intestine is the largest producer of ammonia. It is generated by the intestinal mucosa, from the intraluminal metabolism of amino acids, and through the bacterial degradation of urea and other nitrogenous products. It then enters the portal circulation to the liver for detoxification. Finally, its elimination occurs through the conversion to urea in the liver and to glutamine in the brain and muscle. Urea synthesized in the liver undergoes hydrolysis at the level of the intestine, generating ammonia, which in turn returns to the liver to be converted back into urea. In addition to the urea cycle, the liver also processes ammonia through its use for glutamine synthesis ${ }^{1-3}$.

Several theories try to explain the occurrence of encephalopathy secondary to high levels of ammonia $1,2,4,5$. The cerebral cells most affected by hyperammonaemia are the astrocytes ${ }^{6}$. They are the main carriers of glutamine synthetase in the brain, which is responsible for the conversion of ammonia and glutamate into glutamine ${ }^{4,6}$. In turn, glutamine appears to play a key role in ammonia neurotoxicity in hepatic encephalopathy. Its action occurs either, indirectly, by the formation of reactive oxygen species, or directly, since it causes edema of astrocytes, contributing to cerebral dysfunction associated with hyperammonemia $^{7-9}$. In addition to the damage to astrocytes via the glutamine pathway, ammonia itself is also neurotoxic ${ }^{1,7,8}$.

The presence of acute kidney injury (AKI) can be both the cause and effect of the pathological process that increases blood ammonia levels ${ }^{2}$. In the presence of renal dysfunction, up to $20 \%$ of the daily ammonia excreted at the renal level may be compromised ${ }^{10}$. 
Although there is no clear cut-off of the ammonia blood level that correlates with the presence of neurological signs and symptoms, concentrations above 150-200umol/L appear to be associated with increased intracranial pressure, cerebral herniation and death ${ }^{11}$, especially in the presence of liver failure ${ }^{12}$. Neurological manifestations require prompt intervention.

The role of extracorporeal dialysis in reducing blood ammonia levels and improving cerebral edema is still uncertain. While in children there are some studies that show the effectiveness of various dialysis techniques (peritoneal dialysis, intermittent hemodialysis and continuous techniques), in adults the literature is scarce. There are no established guidelines on which ammonia value justifies initiating extracorporeal dialysis technique (ECDT) or which techniques are more appropriate in the case of hyperammonemic encephalopathy $3,10,13$.

Our case aroused the interest of a multidisciplinary team to the creation of a protocol for patients with encephalopathy due to hyperammonemia, since a good neurological outcome requires a prompt intervention.

\section{CASE REPORT}

Our case describes a 22-year-old, previously healthy, woman, with no known allergies and no drugs or herbal medicines consumption. Besides her 54-year-old father who had type 2 diabetes, she had no other relevant family history.

She presented with polyuria, polydipsia, anorexia, vomiting and significant (>10\%) weight loss over a month. At admission, the patient was hemodynamically stable and presented Kussmaul breathing, slurred speech, but showing orientation to time, place and person. Cold extremities were detected.

Laboratory data revealed hypoglycemia (57 mg/dL), high anion gap metabolic acidosis with severe acidemia, normal lactate, serum creatinine of $1.12 \mathrm{mg} / \mathrm{dl}$ and 261 (N 26-74) umol/l of ammonia. Urine analysis showed ketone bodies,
She evolved with progressive encephalopathy and neurological deterioration. In the presence of hypoglycemic with ketonuria and hyperammonemic encephalopathy, a hereditary metabolic disease was suspected. Lipids and protein ingestion were stopped, and glucose solution, carnitine and benzoate were started. It was decided to start a blood purification technique for ammonia removal and acid-base correction. Continuous venovenous hemodiafiltration (CVVHDF) was performed for 3 days with a drastic neurologic improvement. Table I demonstrates the concomitant evolution of her analytical parameters.

Further investigation was done to find the etiology of the metabolic disorder. Plasma amino acids quantification revealed low counts of valine, leucine, tyrosine and arginine and acylcarnitines dosing showed low free carnitine level and high tetradecanoyl-, tetradecenoyl- and hexadecenoylcarnitine, suggesting a fatty acid beta-oxidation deficit.

She had a full recovery, and at the time of discharge had no neurological changes, with a strict diet free of fat, animal protein and high-protein vegetables, plus supplementation with benzoate, carnitine, riboflavin, maltodextrin and essential amino acids.

Etiologic study was conducted, and a genetic test was performed with a result compatible with type 2 glutaric aciduria. After supplementation, the levels of free carnitine were within the normal range of values $32.83 \mathrm{uM}$ (reference value 19.24-48.48 uM) and the specific plasma acylcarnitines were above the normal range.

\section{DISCUSSION}

Type 2 glutaric aciduria or multiple acyl-CoA dehydrogenase deficiency can present as a hypoketotic hypoglycemia. However, hypoketotic is different from nonketotic and the presence of minimal ketone bodies, as we have seen in this patient in the beginning of the case report, doesn't exclude our diagnosis ${ }^{14}$.

The treatment for acute hyperammonemia should be instituted as soon as possible with the aim of rapidly reducing both the production of nitrogen degradation products and blood ammonia levels.

Table I

Evolution of the analytical parameters during hospital stay

\begin{tabular}{|c|c|c|c|c|c|c|}
\hline & $\begin{array}{c}\text { Day } 0 \\
\text { Admission }\end{array}$ & $\begin{array}{c}\text { Day } 1 \\
\text { CVVHDF }\end{array}$ & $\begin{array}{c}\text { Day } 2 \\
\text { CVVHDF }\end{array}$ & $\begin{array}{c}\text { Day } 3 \\
\text { CVVHDF }\end{array}$ & Day 4 & $\begin{array}{c}\text { Day } 8 \\
\text { Discharge }\end{array}$ \\
\hline $\mathrm{pH}$ & 7.220 & 7.379 & 7.517 & 7.509 & 7.420 & 7.385 \\
\hline pCO2 (mmHg) & 16 & 22 & 28 & 37 & 34 & 38 \\
\hline pO2 (mmHg) & 133 & 134 & 121 & 114 & 110 & 113 \\
\hline $\mathrm{HCO} 3$ (mmol/L) & 11 & 16 & 25 & 30 & 25 & 24 \\
\hline $\mathrm{K}^{+}(\mathrm{mmol} / \mathrm{L})$ & 4.4 & 3.1 & 2.8 & 3.1 & 3.2 & 3.7 \\
\hline Lactate (mmol/L) & 0.3 & 0.3 & 0.8 & 1.0 & 1.2 & 1.1 \\
\hline Anion Gap & 25 & 17 & 17 & 9 & 9 & 14 \\
\hline Glycaemia (mg/dL) & 55 & 66 & 70 & 132 & 146 & 142 \\
\hline Creatinine/ & $1.12 /$ & $0.94 /$ & $0,47 /$ & $0.38 /$ & $0.50 /$ & $0.47 /$ \\
\hline Urea (mg/dL) & 33 & 12 & 6 & 3 & 13 & 14 \\
\hline Ammonia (umol/L) & 261 & 207 & 147 & 39 & 36 & 19 \\
\hline
\end{tabular}

CVVHDF continuous venovenous hemodiafiltration; pCO2 partial pressure of carbon dioxide; pO2 partial pressure of oxygen. 
Rapid rehydration, discontinuation of protein intake and electrolyte and mineral imbalances correction should be performed ${ }^{1,15}$.

The best timing for EBPT initiation in these patients is yet to be defined. However, it has been proposed to start when blood ammonia levels are three times higher than the upper limit of normal or in the presence of severe encephalopathy ${ }^{16}$. Warrilow and Bellomo ${ }^{17}$ suggest that the onset of EBPT should occur in the early stages of hyperammonemia, before the development of AKI. A study carried out in patients with valproic acid intoxication reported clinical improvement when extracorporeal techniques were started within the first 24 hours after admission ${ }^{18}$.

There are important factors that determine whether a toxin or medication can be successfully removed by a dialysis technique, mainly the molecular weight and toxin ability to bind to plasma proteins, particularly albumin ${ }^{2}$. Another factor to be considered is the rebound effect, which consists of the moving of the drug from the extravascular to the intravascular compartment. Ammonia has a low molecular weight $(17 \mathrm{~g} / \mathrm{mol})$ and does not bind significantly to plasma proteins, making it easily dialyzable. However, it has an important rebound effect, that is why, in children, continuous and intermittent techniques have been shown to mitigate this effect and consequently reduce significantly blood ammonia concentrations ${ }^{19}$.

Both continuous and intermittent techniques are effective in removing ammonia, differing only in the removal rate. Intermittent techniques are very effective in rapid ammonia clearance, which is the main reason for their choice ${ }^{17,20}$. They allow a $50 \%$ reduction in blood ammonia concentrations in just 1 to 2 hours, compared to the 2 to 14.5 hours of continuous techniques ${ }^{20}$. Still, other studies favor continuous techniques since they allow a constant removal of ammonia as it is being produced, plus they are associated with greater hemodynamic stability and slower reductions of cerebral ammonia levels ${ }^{2,21}$.
High filtration rates lead to a greater reduction in ammonia concentrations, presumably related to the greater dilution due to the volume of substitution (> 35mL/Kg/hour) ${ }^{10}$.

Some authors suggest that intermittent techniques reduces more effectively ammonia blood levels leading to a more rapid resolution of the encephalopathy, which appears to be a major determinant of short-term outcomes ${ }^{22,23}$. Since ammonia has a high diffusive clearance and because its diffusion rate is largely determined by blood flow $(\mathrm{Qb})$, the use of intermittent techniques allows a higher rate of blood ammonia removal. However, the choice of the technique depends on the availability and experience of each center and on which is possible to start earlier. Continuous techniques should be used in order to prevent rebound and ideally after intermittent technique is discontinued ${ }^{19}$.

It is also important to point out that caution should be taken to avoid alkalosis and hypokalemia since it can lead to increase of $\mathrm{NH}_{3}$ production, which can cross the hematoencephalic barrier, contrarily to $\mathrm{NH}_{4}{ }^{+}$, and exacerbate the encephalopathy ${ }^{2}$.

It is difficult to understand the real impact of a specific intervention in the setting of measures adopted to treat these pathologies, namely metabolic corrections and diets low in protein.

Although the data is inconsistent, the standard of care in hyperammonemia consists of rapid hydration, use of nitrogen chelators and continuous high-dose techniques ${ }^{24,25}$.

At our center, in the presence of patients with hyperammonaemia (blood levels superior to 200umol/L) and severe encephalopathy, with suspicion of an associated enzyme deficit, an EBPT is began as soon as possible. If the patient is hemodynamically stable, we prefer to initiate a prolonged intermittent technique (SLED - sustained low efficiency

\section{Table II}

Studies into EBPT use in the setting of acute hyperammonemic encephalopathy

\begin{tabular}{|c|c|c|c|c|c|}
\hline Study & Patients & Renal replacement therapy & Blood flow rate & Dialysate flow & Population \\
\hline Schaefer et al, $1999^{27}$ & 7 & CVVHD & $10-40 \mathrm{ml} / \mathrm{min}$ & $1-51 / h$ & Newborns \\
\hline Rajpoot et al, $2004^{28}$ & 4 & IHD & $15-30 \mathrm{ml} / \mathrm{min}$ & ND & Newborns \\
\hline Mcbryde et al, $2006^{19}$ & 18 & CVVHD, HD, DP (21) & 5 to $8 \mathrm{ml} / \mathrm{Kg} / \mathrm{min}$ & $2000 \mathrm{ml} / 1.73 \mathrm{~m} 2 /$ hour & Children \\
\hline Lai et al, $2007^{20}$ & 8 & $\begin{array}{c}\text { CVVH (7), CAVH (2), CVVHD (1), } \\
\text { HD (1), DP (2) }\end{array}$ & 16 to $100 \mathrm{ml} / \mathrm{min}$ & $999 \mathrm{ml} /$ hour & Children \\
\hline Arbeiter et al, $2010^{29}$ & 21 & $\begin{array}{l}\text { CVVHD (17) } \\
\text { DP (4) }\end{array}$ & $5-15 \mathrm{ml} / \mathrm{Kg} / \mathrm{min}$ & $2000 \mathrm{ml} / 1.73 \mathrm{~m} 2 /$ hour & Mostly newborns \\
\hline Westrope et al, $2010^{30}$ & 14 & CVVH (14) & $>25 \mathrm{ml} / \mathrm{min}(6-24 \mathrm{ml} / \mathrm{Kg} / \mathrm{min})$ & ND & Newborns \\
\hline Fleming et al, $2012^{24}$ & 50 & $\begin{array}{l}\text { CVVH (8), CVVHD (26), } \\
\text { CVVHDF (16) }\end{array}$ & ND & ND & Children \\
\hline Spinale et al, $2013^{25}$ & 2 & $\begin{array}{l}\text { CVVHD (1) } \\
\text { CVVHDF (1) }\end{array}$ & $\begin{array}{l}30 \mathrm{ml} / \mathrm{min} \\
40 \mathrm{ml} / \mathrm{min}\end{array}$ & $\begin{array}{c}8650 \mathrm{ml} / \mathrm{h} / 1.73 \mathrm{~m} 2(1000 \mathrm{ml} / \mathrm{h}) \\
900 \mathrm{ml} / \mathrm{h}\end{array}$ & Newborns \\
\hline Picca et al, $2015^{22}$ & 45 & $\begin{array}{c}\text { CVVHD (14) } \\
\text { CAVHD (5) } \\
\text { IHD (3) } \\
\text { PD (23) }\end{array}$ & ND & $\begin{array}{c}2 \mathrm{l} / \mathrm{h} \\
0.5 \mathrm{l} / \mathrm{h} \\
500 \mathrm{ml} / \mathrm{min}\end{array}$ & Newborns \\
\hline Cavagnaro Santa Maria et al, $2018^{31}$ & 6 & $\begin{array}{l}\text { CVVH (2) } \\
\text { CVVHDF (4) }\end{array}$ & $>30-50 \mathrm{ml} / \mathrm{min}(8-20 \mathrm{ml} / \mathrm{Kg} / \mathrm{min})$ & $2000-2500 \mathrm{ml} / 1.73 \mathrm{~m} 2 / \mathrm{h}$ & Newborns \\
\hline
\end{tabular}

PD: peritoneal dialysis, IHD: intermitent hemodialysis; CVVH: continuous venovenous hemofiltration; CVVHD: continuous venovenous hemodialysis; CVVHDF continuous venovenous hemodiafiltration. 
dialysis), given the greater capacity of ammonia purification rate. But if hemodynamic instability is present, we would elect a continuous technique (CRRT - continuous renal replacement therapy) and although it has a lower ammonia removal rate, it would avoid the rebound effect. Moreover, although not performed at our center, in case of hemodynamic stability, one could consider a hybrid protocol with intermittent hemodialysis followed by a continuous technique in order to maximize ammonia removal plus avoid the rebound effect ${ }^{26}$.

According to the experience of the staff of the intensive care unit on the day of the admission, CRRT was the modality selected, even though our patient was hemodynamically stable.

Serum dosage of ammonia should be performed before and after the technique. The ECDT is suspended when the maintenance of the plasma ammonia concentration is below $100 \mathrm{umol} / \mathrm{L}$ after, at least, 12 hours of technique suspension, and if there is concomitant neurological improvement.

Our SLED scheme consists of the use of Qb from 100 to $200 \mathrm{~mL} / \mathrm{min}$ with a dialysate flow (Qd) of $300 \mathrm{ml} / \mathrm{min}$ for a 10 -hour period. When we use CRRT, and considering ammonia's low molecular weight, we give primacy to a technique with a diffusion mechanism, as CVVHD and $\mathrm{CVVHDF}^{26}$. If we consider CVVHDF, we aim to reach a replacement volume superior to $35 \mathrm{ml} / \mathrm{Kg} / \mathrm{h}$ in post dilution. For both techniques we use bicarbonate-based solutions with a high level of potassium, in order to reach values between 4 and $4,5 \mathrm{mmol} / \mathrm{L}$. The choice of hypocoagulation is made individually according to each patient characteristics.

Table II summarizes the studies published to date in the field of the use of EBPT for the management of acute hyperammonemic encephalopathy.

\section{CONCLUSION}

Hyperammonemia in adults is usually associated with liver failure rather than with metabolic disorders, as in our patient.

In the presence of encephalopathy, EBPT should be considered. Ammonia, as urea, is a small molecule and does not bind significantly to proteins, and is easily dialysable either by intermittent or continuous techniques. Although greater $\mathrm{Qb}$ can be achieved by intermittent hemodialysis, CVVHDF offers a more continuous clearance, with less rebound effect.

Disclosure of potential conflicts of interest: none declared.

\section{References:}

1. Auron A, Brophy PD. Hyperammonemia in review: pathophysiology, diagnosis, and treatment. Pediatr Nephrol. 2012;27(2):207-222. doi:10.1007/s00467-011-1838-5

2. Gupta S, Fenves AZ, Hootkins R. The Role of RRT in hyperammonemic patients. CJASN. 2016;11(10):1872-1878. doi:10.2215/CJN.01320216

3. Tapper EB, Jiang ZG, Patwardhan VR. Refining the ammonia hypothesis. Mayo Clinic Proceedings. 2015;90(5):646-658. doi:10.1016/j.mayocp.2015.03.003

4. Jayakumar AR, Rama Rao KV, Schousboe A, Norenberg MD. Glutamine-induced free radical production in cultured astrocytes. Glia. 2004;46(3):296-301. doi:10.1002/glia.20003

5. Lichter-Konecki U, Mangin JM, Gordish-dressman H, Hoffman EP, Gallo V. Gene expression profiling of astrocytes from hyperammonemic mice reveals altered pathways for water and potassium homeostasis in vivo. Glia. 2008;56(4):365-377. doi:10.1002/glia.20624
6. Norenberg MD. Astroglial dysfunction in hepatic encephalopathy. Metabolic Brain Disease. 1998;13(4):319-335. doi:10.1023/A:1020688925901

7. Shawcross $D$, Jalan R. The pathophysiologic basis of hepatic encephalopathy: central role for ammonia and inflammation. Cell Mol Life Sci. 2005-62(19-20):2295-2304 doi:10.1007/s00018-005-5089-0

8. Norenberg MD. Astrocyte Responses to CNS Injury: Journal of Neuropathology and Experimental Neurology. 1994;53(3):213-220. doi:10.1097/00005072-199405000-00001

9. Balata S. Induced hyperammonemia alters neuropsychology, brain MR spectroscopy and magnetization transfer in cirrhosis. Hepatology. 2003;37(4):931-939. doi:10.1053/jhep.2003.50156

10. Slack AJ, Auzinger $\mathrm{G}$, Willars $C$, et al. Ammonia clearance with haemofiltration in adults with liver disease. Liver Int. 2014;34(1):42-48. doi:10.1111/liv.12221

11. Clemmesen JO, Larsen FS, Kondrup J, Hansen BA, Ott P. Cerebral herniation in patients with acute E liver failure is correlated with arterial ammonia concentration. Hepatology. 1999;29(3):648-653. doi:10.1002/hep.510290309

12. Ozanne B, Nelson J, Cousineau J, et al. Threshold for toxicity from hyperammonemia in critically ill children. Journal of Hepatology. 2012;56(1):123-128. doi:10.1016/j.jhep.2011.03.021

13. Gotthardt $\mathrm{D}$, Riediger $\mathrm{C}$, Weiss $\mathrm{KH}$, et al. Fulminant hepatic failure: etiology and indications for liver transplantation. Nephrology Dialysis Transplantation. 2007;22(8):viii5-viii8. doi:10.1093/ndt/gfm650

14. Merritt IL, Chang IJ. Medium-Chain Acyl-Coenzyme A Dehydrogenase Deficiency. In: Adam MP, Ardinger HH, Pagon RA, et al., eds. GeneReviews ${ }^{\oplus}$. University of Washington, Seattle; 1993. Accessed January 20, 2021. http://www.ncbi.nlm.nih.gov/books/NBK1424/

15. Summar M, Tuchman M. Proceedings of a consensus conference for the management of patients with urea cycle disorders. The Journal of Pediatrics. 2001;138(1):S6-S10. doi:10.1067/ mpd.2001.111831

16. Machado MCC, Fonseca GM, Jukemura J. Late-onset ornithine carbamoyltransferase deficiency accompanying acute pancreatitis and hyperammonemia. Case Reports in Medicine. 2013;2013:1-3. doi:10.1155/2013/903546

17. Warrillow SJ, Bellomo R. Preventing cerebral oedema in acute liver failure: the case for quadruple- $h$ therapy. Anaesthesia and Intensive Care. 2014:42(1):78-88 doi:10.1177/0310057X1404200114

18. Ghannoum M, Laliberté $M$, Nolin TD, et al. Extracorporeal treatment for valproic acid poisoning: systematic review and recommendations from the EXTRIP workgroup. Clinical Toxicology. 2015;53(5):454-465. doi:10.3109/15563650.2015.1035441

19. McBryde KD, Kershaw DB, Bunchman TE, et al. Renal replacement therapy in the treatment of confirmed or suspected inborn errors of metabolism. The Journal of Pediatrics. 2006;148(6):770-778. doi:10.1016/j.jpeds.2006.01.004

20. Lai Y-C, Huang H-P, Tsai I-J, Tsau Y-K. High-volume continuous venovenous hemofiltration as an effective therapy for acute management of inborn errors of metabolism in young children. Blood Purif. 2007;25(4):303-308. doi:10.1159/000106102

21. Davenport A, Will EJ, Davison AM. Early changes in intracranial pressure during haemofiltration treatment in patients with grade 4 hepatic encephalopathy and acute oliguric renal failure. Nephrology Dialysis Transplantation. 1990;5(3):192-198. doi:10.1093/ndt/5.3.192

22. Picca S, Dionisi-Vici C, Bartuli A, et al. Short-term survival of hyperammonemic neonates treated with dialysis. Pediatr Nephrol. 2015;30(5):839-847. doi:10.1007/s00467-014-2945-x

23. Msall M, Batshaw ML, Suss R, Brusilow SaulW, Mellits ED. Neurologic outcome in children with inborn errors of urea synthesis: outcome of urea-cycle enzymopathies. N Engl J Med. 1984;310(23):1500-1505. doi:10.1056/NEJM198406073102304

24. Fleming GM, Walters S, Goldstein SL, et al. Nonrenal indications for continuous renal replacement therapy: areport from the Prospective Pediatric Continuous Renal Replacement Therapy Registry Group. Pediatric Critical Care Medicine. 2012;13(5):e299-e304. doi:10.1097/PCC.0b013e31824fbd76

25. Spinale JM, Laskin BL, Sondheimer N, Swartz SJ, Goldstein SL. High-dose continuous renal replacement therapy for neonatal hyperammonemia. Pediatr Nephrol. 2013;28(6):983-986. doi:10.1007/ s00467-013-2441-8

26. Raina R, Bedoyan JK, Lichter-Konecki U, et al. Consensus guidelines for management of hyperammonaemia in paediatric patients receiving continuous kidney replacement therapy. Nature Reviews Nephrology. 2020;16(8):471-482. doi:10.1038/s41581-020-0267-8

27. Schaefer F. Dialysis in neonates with inborn errors of metabolism. Nephrology Dialysis Transplantation. 1999;14(4):910-918. doi:10.1093/ndt/14.4.910

28. Rajpoot DK, Gargus JJ. Acute hemodialysis for hyperammonemia in small neonates. Pediatric Nephrology. 2004;19(4):390-395. doi:10.1007/s00467-003-1389-5

29. Arbeiter AK, Kranz B, Wingen AM, et al. Continuous venovenous haemodialysis (CVVHD) and continuous peritoneal dialysis (CPD) in the acute management of 21 children with inborn errors of metabolism. Nephrology Dialysis Transplantation. 2010;25(4):1257-1265. doi:10.1093/ndt/gfp595

30. Westrope C, Morris K, Burford D, Morrison G. Continuous hemofiltration in the control of neonatal hyperammonemia: a 10-year experience. Pediatr Nephrol. 2010;25(9):1725-1730. doi:10.1007/ s00467-010-1549-3

31. Cavagnaro Santa María F, Roque Espinosa J, Guerra Hernández P. Uso de hemofiltración veno-venosa continua en neonatos con hiperamonemia. Serie clínica. Rev chil pediatr. 2018;89(1):7478. doi:10.4067/S0370-41062018000100074

\section{Correspondence to:}

Filipa Silva, MD

E-mail: filipasofiasantossilva@gmail.com

Joana Tavares, MD

E-mail: joanatavares91@gmail.com

Serviço de Nefrologia, Centro Hospitalar Universitário do Porto

Largo do Prof. Abel Salazar

4099-001 Porto, Portugal 